\title{
Seismic pads to protect buildings and structures from bulk seismic waves
}

\author{
Vladislav Vershinin", Saruul Javkhlan and Suhaibi Saidmukaram \\ Moscow State University of Civil Engineering, Yaroslavskoe shosse, 26, Moscow, 129337, Russia
}

\begin{abstract}
The issues of using seismic pads to protect buildings and structures from bulk seismic $\mathrm{P}$ and $\mathrm{S}$ waves are analyzed. Considered are historical counterparts including the famous Imperial Hotel in Tokyo. The prospects are noted for the use of seismic pads providing the best protective properties and greater durability, comparable to the lifetime of the entire structure, as well as, most importantly, the protection of the structure and its foundation structures that remain unprotected using various types of seismic isolators.
\end{abstract}

\section{Introduction}

Seismic pads located under the foundation of the structure are designed to protect the entire structure, including foundation structures, from bulk seismic P and S waves. Protection of foundation structures is one of the main advantages of systems built on the basis of seismic pads over seismic isolators of various types - the latter leave the foundation structures virtually unprotected, that can lead to off-design stresses in the base plates and, as a result, cause the destruction of the base plates and the entire structure. Another indisputable advantage of most systems based on seismic pads is their durability, comparable to the lifetime of the entire structure, unlike the most common rubber-metal seismic isolators, whose service life is usually limited to 20-25 years.

The term "seismic cushion" in the literature on seismic protection apparently first appeared in connection with the construction of the Imperial Hotel in Tokyo (Japan) in 1923, see Fig. 1.

The hotel was built on relatively dense soils, but below the $6 \mathrm{~m}$ mark down to the depths of 10-12 $\mathrm{m}$ there were weak silt soils due to the marsh that was once on this place. In September 1923 one of the most destructive earthquakes of magnitude $\mathrm{M}_{\mathrm{w}}=7.9-8.2$ occurred in Tokyo causing tens of thousands of people to die and mass destruction: according to Japanese insurance companies more than $80 \%$ of buildings with reinforced concrete or steel frames were recognized as having certain destruction. An even greater percentage of damage was recorded in brick and stone structures, Fig 2.

At a subsequent seismological conference (1925, Japan) structures that withstood the consequences of the Great Tokyo earthquake of 1923 were analyzed and it was noted that soft and pliable soils under the base of the Imperial Hotel building served as a kind of "seismic pad" that prevented penetration of seismic waves (mainly bulk S-waves) to the

\footnotetext{
*Corresponding author: vlodya_91@mail.ru
} 
foundation of the structure.

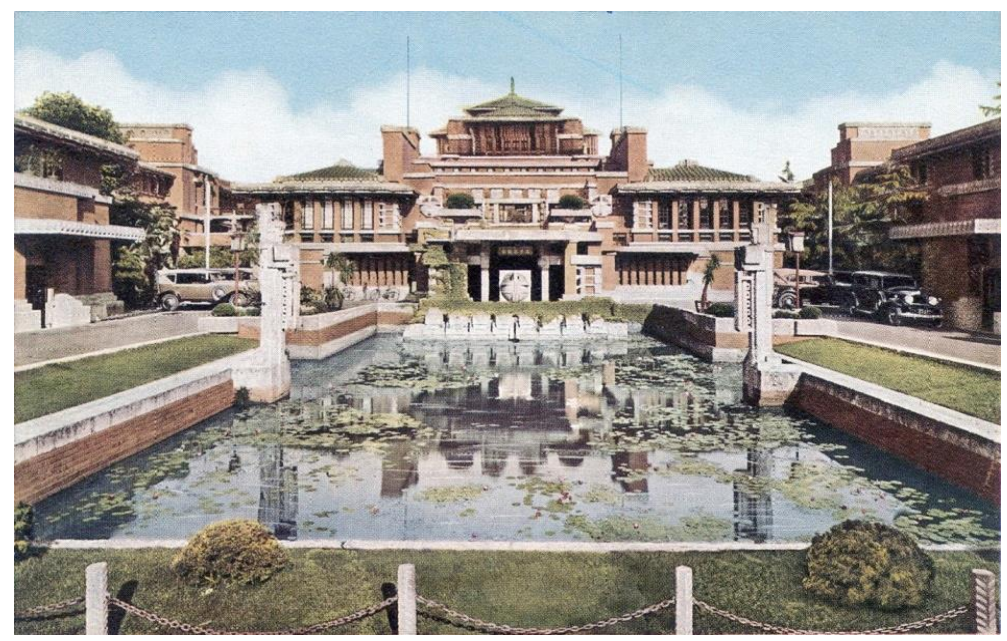

Fig. 1. Imperial Hotel, architect Frank Lloyd Wright [1]

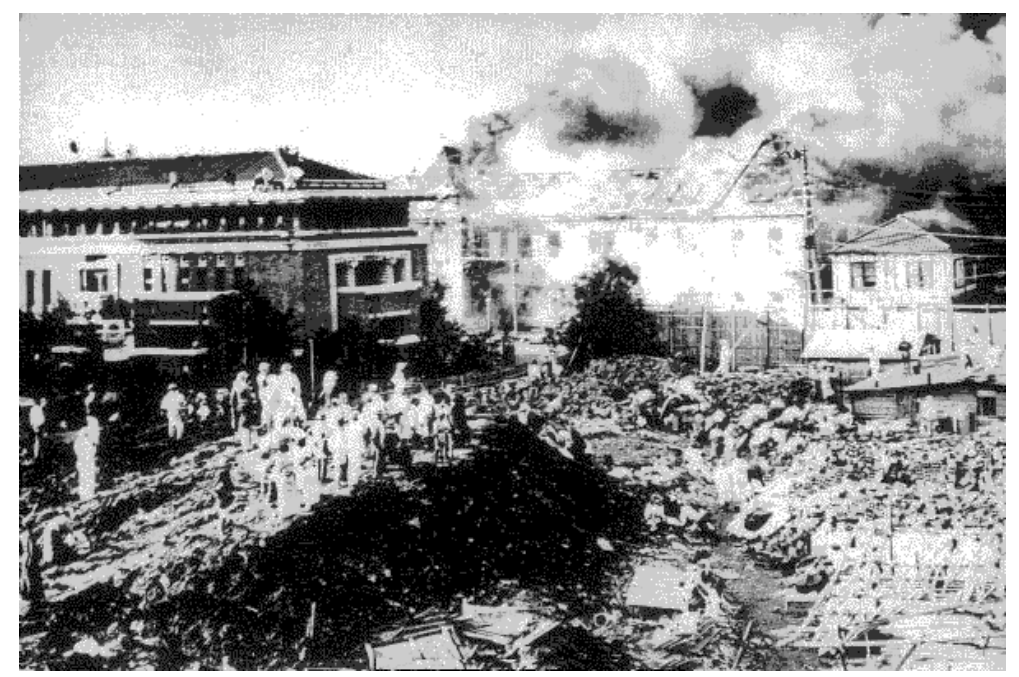

Fig. 2. Destroyed buildings near the hotelby the earthquake $M_{w} 7.9-8.2$ (September 1923)

Subsequently the idea of using weak soils under the base of the structure, later called the base with a "floating foundation" or a "seismic pad", was reflected in studies [2-4]. In these studies it was noted that along with the positive factors contributing to the dissipation of seismic energy weak soils located at a certain depth under the base of the structure, especially if their thickness exceeds several meters (more than $2 \mathrm{~m}$ ), are capable of causing significant effects, such as dynamic uneven structures settlement. In addition such arrays of weak soils under seismic events can liquefy and loss their bearing capacity. To eliminate these negative factors it is recommended to reduce the thickness of the cushion to values less than one meter $[5,6]$ and to perform the cushion of materials that retain their dissipative properties at significant pressures. In practice the requirement to reduce the thickness of the cushion while maintaining good dissipative properties with respect to the energy of seismic waves means the rejection of the use of natural gravel-sand materials. Instead of natural gravel-sand materials the use of artificial materials with the properties of 
dissipation of waves energy within specified frequency ranges is recommended. Further, following [7], such materials will be called seismic metamaterials.

In seismic dynamics such metamaterials, which provide stable energy dissipation of seismic waves in a wide range of frequencies, are often referred to as metamaterials with the properties of wide-range phonon crystals [8], since they allow the energy of seismic waves to be absorbed in a wide frequency range. For general purpose building structures the frequency range at which energy absorption is required is usually $2-15 \mathrm{~Hz}$, and for special structures the corresponding frequency range is $2-35 \mathrm{~Hz}$.

Seismic pads are used to protect bridge piers, in particular piers of the longest cablestayed bridge Rion-Antirion across the Gulf of Corinth (Greece), Fig. 3 [9, 10].

When creating this bridge pads made of special granular materials were placed under its supports allowing them to dissipate the energy of seismic S-waves and reflect the energy of seismic P-waves. A recent powerful earthquake in southern Greece $\left(M_{w}=6.5\right)$ with an epicenter just $36 \mathrm{~km}$ from one of the piers of the bridge did not cause any damage to the piers and the span of the bridge, which confirmed the correctness of the decision on seismic pads under the bridge piers that dissipate seismic waves energy.

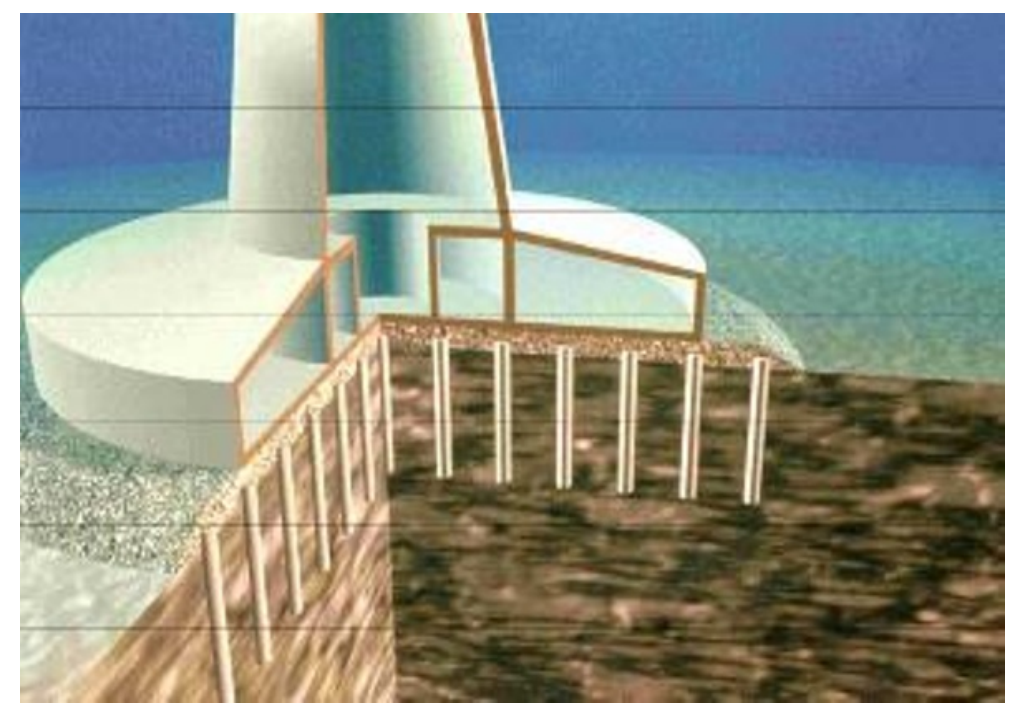

Fig. 3. Seismic pad for Rion-Antirion bridge [9, 10]

\section{Constructive solutions based on seismic pads used for seismic protection}

Nowadays design solutions based on the use of seismic pads are being implemented by a number of companies, Marathon Alliance (Australia), FIP Industriale (Italy), Bridgestone (Japan), MM Systems Corp (USA), Kawakin Core Tech (Japan) are among them.

Production of metamaterials with given dissipative properties is carried out by the companies Marathon Alliance (Australia), Bridgestone (Japan), Raith Nanofabrication (Germany), Roditi (United Kingdom).

The estimated costs of some sample projects are given below.

- Protection of a high-rise Brookfield Place Tower in Perth (Australia) with a seismic pad. The base of the skyscraper with a shopping complex and an underground parking is $20000 \mathrm{~m}^{2}$ in area, the design pressure under the foundation is $35 \mathrm{kPa}$, the thickness of the seismic pad made of metamaterials with the properties of wide-range phonon 
crystals is $0.45 \mathrm{~m}$. The total cost of the building is 600 million USD, the seismic protection costs 15 million USD ( $2.5 \%$ of the total structure cost), the calculated decrease in acceleration amplitudes is 2.4 times (by more than a point).

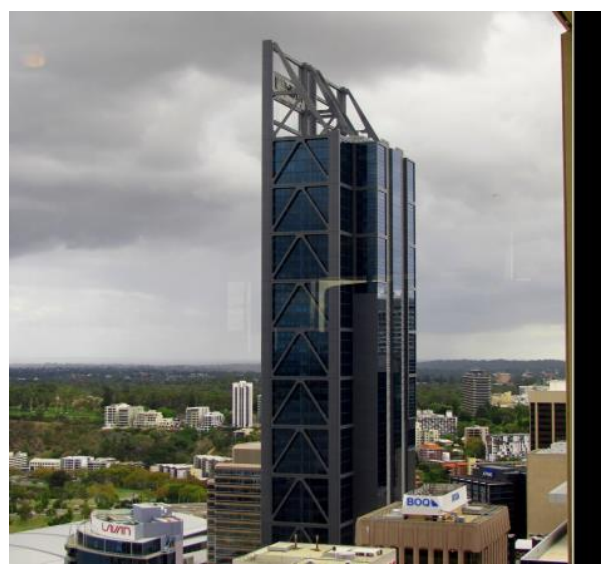

Fig. 4. High-rise Brookfield Place Tower in Western Australia

- Protection of the Central Hospital in Wellington (New Zealand) with the help of seismic pads under the building supports. The area of the base of the hospital and underground parking is $14000 \mathrm{~m}^{2}$, the design pressure under the foundation supports is $33 \mathrm{kPa}$, the seismic pads thickness is $0.4 \mathrm{~m}$. The cost of the whole complex is 350 million USD, the seismic protection costs 7 million USD ( $2 \%$ of the cost of the whole structure), the calculated decrease in acceleration amplitudes is 4.2 times (by more than two points).

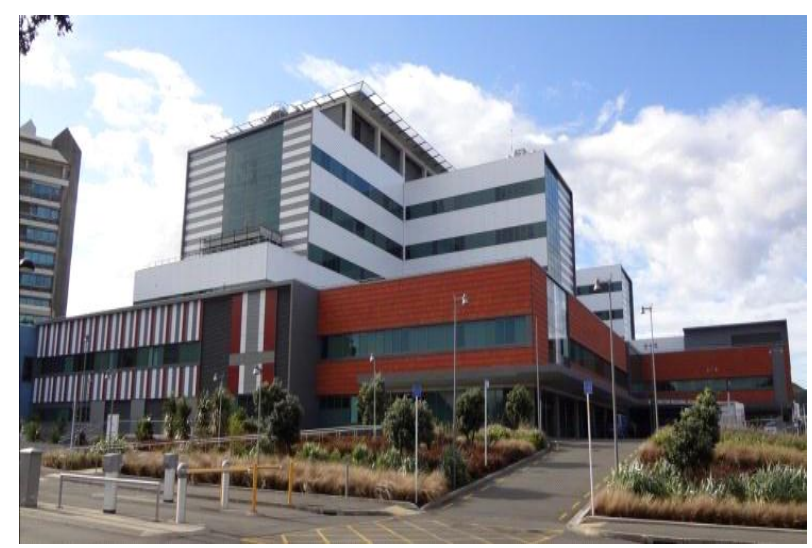

Fig. 5. Central Hospital in Wellington (New Zealand)

- Protection of the Women's Hospital in Christchurch (New Zealand) with a seismic pad under the base of the building. The protected area is $2500 \mathrm{~m}^{2}$, the design pressure under the foundation is $35 \mathrm{kPa}$, the thickness of the seismic pad is $0.4 \mathrm{~m}$. The cost of the hospital complex is 120 million USD, the seismic protection costs 2.1 million USD (1.8\% of the cost of the entire structure), the estimated reduction in acceleration amplitudes is 2.3 times (by more than a point). 


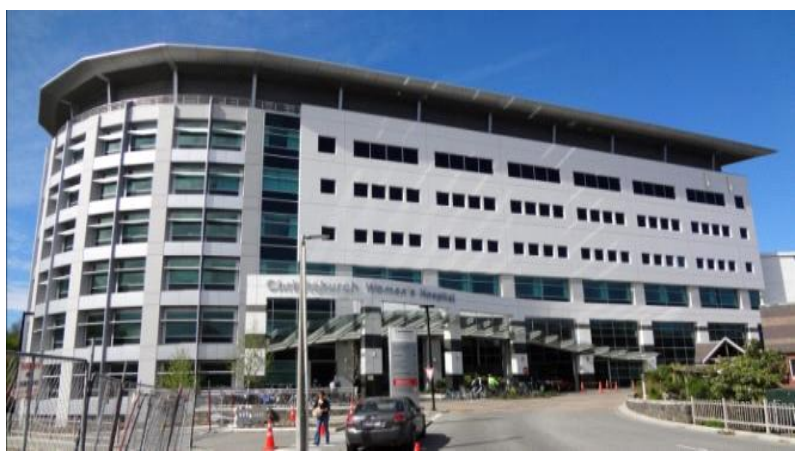

Fig. 6. Women's Hospital in Christchurch (New Zealand)

The relative cost of the considered seismic protection systems ranges from 1.8 to $3 \%$ of the entire structure cost, which does not exceed the recommended $4 \%$ of the cost of seismic protection systems.

\section{Conclusion}

In conclusion it should be noted that the analyzed seismic protection system has several undeniable advantages:

1) Protection of foundation structures

Seismic pads allow one to protect both the superstructure and the substructure, while known solutions based on seismic isolators leave the foundation structures unprotected.

2) Durability

Developed metamaterials with the properties of wide-range phonon crystals used to fill seismic barriers and seismic pads are made of melts of inorganic materials containing only basalt and quartz components. These materials maintain the specified operating conditions for more than 250 years, which corresponds to or exceeds the estimated service life of buildings and structures. At the same time the typical estimated service life of rubber-metal seismic isolators does not exceed 25-30 years, which is mainly caused by the degradation of rubber properties.

3) Range of damped frequencies

Seismic pads have the ability to dissipate the energy of seismic waves in a wide range of frequencies. For basic types of civil and industrial buildings this is $2-15 \mathrm{~Hz}$. In the case of atomic energy facilities the frequency range can be extended to 2-35 Hz. At the same time all the main types of seismic isolators due to the peculiarities of their design solutions are tuned to a narrower frequency range with non-uniform amplitudefrequency characteristic.

4) Constant frequency spectrum of the structure

The use of seismic pillows allows one to keep the spectrum of natural frequencies and natural forms of oscillations of the building unchanged, since the pads are located outside the structure. At the same time the use of seismic isolators of various types shifts the spectrum of natural frequencies to lower values and, accordingly, makes adjustments to the natural modes of vibration, which can lead to the appearance of unexpected resonances at lower frequencies.

5) Cost

Due to their durability seismic pads have another advantage over seismic isolators: at a comparable initial cost they significantly benefit in value to rubber-metal seismic isolators after the necessary one-time replacement of the latter after 20-25 years of operation. 


\section{References}

1. M. Secrest, Frank Lloyd Wright: A Biography (University of Chicago Press, 1998, 652 p.).

2. D.D. Barkan, Dynamics of Bases and Foundations (N.Y., McGraw Hill, 1962, 434 p.).

3. J.P. Wolf, Dynamic Soil-Structure Interaction. Prentice-Hall International Series in Civil Engineering and Engineering Mechanics (Prentice-Hall, 1985, 466 p.).

4. M.M. Buhler, Soil Dynamics and Foundation Modeling: Experimental and Numerical Investigation of Soil-Foundation-Structure Interaction during Monotonic, Alternating and Dynamic Loading (Independently published, 2017, 304 p.).

5. A. Kaleem, Dynamic Soil-Structure Interaction (LAP LAMBERT Academic Publishing, 2011, 100 p.).

6. Soil-Structure Interaction (Developments in Geotechnical Engineering) (Elsevier, 2014, 384 p.).

7. J.N. Grima, R. Caruana-Gauci, Nature Mater., 11, 565-566 (2012).

8. T. Antonakakis, R.V. Craster, S. Guenneau, J. Mech. Phys. Solids, 71, 84-96 (2014).

9. S. Infanti, P. Papanikolas, M.G. Castellano, Proceedings of 8th World Seminar on Seismic Isolation, Energy Dissipation and Active Vibration Control of Structures, 1-6 (Yerevan, 2003).

10. A. Pecker, $4^{\text {th }}$ Athenian Lecture on Geotechnical Engineering, 1-23 (2006).

11. Information from Marathon Alliance Co. booklet on metamaterials for seismic pads and seismic barriers http://www.marathonalliance.com.au/metamaterials

12. Information from Bridgestone Co. booklet on steel-rubber bearings for seismic protection

http://www.bridgestone.com/products/diversified/antiseismic_rubber/method.html 